\title{
Illegal Drug offenses among Children in Batangas, Philippines: A Narrative Introspection
}

\author{
Dairen P. De Luna ${ }^{1}$, Maria Luisa A. Valdez², Chin Chin H. Diaz ${ }^{3}$ \\ ${ }^{1,2}$ Department of Communication, Batangas State University ARASOF-Nasugbu, Batangas, Philippines
${ }^{3}$ Department of Psychology, Batangas State University ARASOF-Nasugbu, Batangas, Philippines
}

Received: 23 Sept 2020; Received in revised form: 14 Nov 2020; Accepted: 19 Nov 2020; Available online: 28 Nov 2020 (C)2020 The Author(s). Published by Infogain Publication. This is an open access article under the CC BY license (https://creativecommons.org/licenses/by/4.0/).

\begin{abstract}
The increasing number of children in conflict with law (CICL) and the current move in the Philippine legislative branch to lower down the criminal liability age to 9 or 12 years old necessitates the need to reexamine why children commit crimes using a different lens. The study aimed to describe the recurring themes in the lived experiences of male and female CICL with drug-related cases and to propose a gender-responsive framework as basis for the development of programs for CICL. Using the qualitative research design, the study focused on 5 male and 3 female CICL custodies of various Bahay Pagasa in Batangas. The qualitative data were analyzed using coding and narrative analysis framework particularly following the Holistic-Content approach. The male CICL lack parental attachment and bond which has reinforced influence of delinquent peers and adoption of deviant behaviors while the absence of maternal guidance and experience of violence inside the home among female CICL has catalyzed the desire to escape and strengthen attachment to delinquent peers. Considering these, a gender-responsive framework that focuses on equality of access and opportunities as well as gender-sensitive interventions and facilities are endorsed.
\end{abstract}

Keywords-Children in Conflict with Law, Illegal Drug Offenses, Gender-responsive Framework, Narrative Analysis.

\section{INTRODUCTION}

The burgeoning statistics of children in conflict with law (CICL) is alarming. Data from the Philippine National Police revealed that as of July 2016 more than 26,000 children are involved in drugs, a portion as drug couriers or traders and most are drug users. In the same report, an increasing trend is likewise evident in Region IV-A and the province of Batangas.

In an attempt to curtail this scenario, Philippine Congress is pushing for the amendment of Juvenile Justice and Welfare Act of 2006 (JJWA) or Republic Act 9344 (as amended by Republic Act 10630) and lower the minimum age of criminal liability from 15 years to 9 years old only. On the other hand, advocates of children's rights argue that strict implementation of the law is needed instead of simply amending it. A number of studies [1] [2] show that the phenomenon is not simply a case of linear causation.
Considering this, there is a need to understand the gravity of the problem holistically taking into consideration the interdependence and interconnection of many factors. For example, although majority of CICL are male, the number of female offenders is starting to build up. In fact, the 2015 Evaluation of the Intervention and Rehabilitation Program in Residential Facilities and Diversion Programs for Children in Conflict with the Law revealed that the majority of the rehabilitation programs and facilities in the Philippines only cater to male CICL. As such, this research initiative investigated why children in the Batangas Province commit drug-related offenses using the narrative framework and gender lens to identify recurring themes in their live experiences with the end view of developing a gender-based framework as basis of an intervention program for CICL. 
Under the 2017 National Priority Plan and the Juvenile Justice and Welfare Act of 2006, the Department of Social Welfare and Development (DSWD) has been tasked as the lead agency to spearhead programs relative to the Aftercare, Reintegration and Transformation Support Services for Recovering Drug Dependents including children involved in drugs. Institutionally, this study supports the thrust to develop Batangas State University as a leading gender-responsive higher education institution in the province and region.

As defined in the Juvenile Justice and Welfare Act of 2006, a Child in Conflict with the Law (CICL) refers to "a child who is alleged as, accused of, or adjudged as, having committed an offense under Philippine laws." CICL's are habitual youth offenders, delinquents and recidivists who were arrested due to serious criminal acts for more than four times [3]. Though the actual number of CICL cases is still unidentified, data from the Philippine National Police indicates an increasing trend in the number of child law offenders whose cases range from theft to rape from 2006 to 2012 .

The research of Save the Children UK in 2004 covering the areas of Metro Manila, Cebu City and Davao City showed an increasing trend in drug-related offenses of CICL, which is the second most common offense among the female respondents [4]. The report likewise discussed the concept of restorative justice system and diversion as alternative methods in handling CICL cases. One of the many findings of the study included the challenge to reassess existing practices in order to explore new and creative solutions, review current policies, programs and practices, and restructure systems and organizations. This way, the issues of CICL may be better addressed in a manner that is more relevant and responsive to the rights of children.

The study was anchored on Terence P. Thornberry's Interactional Theory which is based on the premise that human behavior occurs in social interaction and can be explained by models that focus on interactive processes [5]. Thornberry's Interactional Theory provides theoretical guidance and a point of departure for the study. The said theory underscored that delinquent behavior is formed by the relationships with other people and social institutions over time. That is, delinquent behavior is explained as a causal network not only affected by social factors but also affecting the development of those social factors.

\section{LITERATURE REVIEW}

There had been a number of studies conducted to shed indepth understanding on the issue of CICL. Various ISSN: 2456-7620 methodologies had been employed such as interviews, case studies, surveys, and documentary reviews conducted in most metropolises in the country. A review of these studies reveals not only commonalities in methods but variance in objectives, respondents, and locale of the study.

Yang et al.'s study [6] assessed the skills of social workers in LGU's in evaluating the capacity of CICL to commit an offense, determine good practices in the current practices and delivery of services to CICL, and propose specific recommendations in terms of programs and policies. Employing the mixed method of research, the study revealed that the majority of the programs in the centers cater only to male CICL which is a reflection of the ratio of male and female CICL in the country. Based on the results of the study, it is tantamount to establish a monitoring and reporting system on the numbers of CICL, which should be gender and age-disaggregated. Considering this findings and the escalating number of female offenders, it cannot be denied that there is a need to delve into a data which reflects female CICL as well.

The study of the British Psychological Society [7] determined how evident is the need for a sense of belonging among alcoholics and drug dependents. This qualitative research analyzed interview transcripts from 21 adults in residential treatment for alcohol and other drug problems. Findings of the study revealed two separate trajectories into and out of addiction. Identity gain pathway provides isolated people with a sense of new social identity and sense of belonging in substance use and addiction while identity loss pathway is evident when previously positive social groups and identities such as being a student, parent, or worker are lost at the onset of addiction. This loss may be in the form of a broken marriage, job loss and loss of custody of their children. Furthermore, drug or alcohol addiction connotes negative identity and stereotypes.

Likewise, Sinha's [8] paper centered primarily on determining the association between stress and addiction in order to develop new prevention and treatment strategies to address vulnerability to addiction. Findings of the study identified stressors in the form of highly and emotionally distressing events that are uncontrollable and unpredictable for both children and adults. The themes range from loss, violence, and aggression to poor support, interpersonal conflict, isolation, and trauma. There is also evidence on the proportional relationship between stressors and addiction such that drug use and abuse is utilized as strategy to cope with stress, to reduce tension, to selfmedicate, and to decrease withdrawal-related distress. 
In terms of the role of parents and peers in the development of a child, Fuligni and Eccles [9] investigated the relationship between the perception of children towards parent-child relationship during early adolescence and early adolescents' perception towards parents and peers. A total of 1,771 children completed self-report questionnaires during their 6 th and 7 th grades. As hypothesized, the likelihood towards extreme form of peer orientation is higher for early adolescents who believed their parents asserted and did not relax their power and restrictiveness. The study likewise revealed the importance of adjusting parent-child relationships during puberty stage and observed a case of extreme peer orientation where adolescents put high value to peer acceptance, recognition and maintenance of peer network to the point of parental disobedience and personal growth obstruction.

Similarly, Okundaye et al. [10] investigated the relationship of familial involvement and drug selling, which revealed that youth involved in drug selling had weaker familial relationship than those uninvolved in the trade. Furthermore, the study found that involved youth expressed stronger sentiments of anger when discussing their mother or father in the interview. The study pointed that a number of research studies connects the influence of parents and family to youth's decision to sell drugs. However, the article of Glenn and Castle [11] cited that teenagers can rebel against society or against adult authority on either a large or small scale.

On the same page, the study of Alboukordi et al. [12], investigated the relationship between and among family structure, parental monitoring and association with delinquent peers to predict delinquency. In this crosssectional study, ninety-six delinquent adolescents and ninety-one non-delinquent adolescents in Tehran, Iran were chosen as respondents through convenient sampling. They completed the parental monitoring inventory and affiliation with delinquent peers' scale. Results of the study showed that 51 percent of delinquents reported distress in the structure of their families which indicates that the latter could be a predictor of the former. Findings of the study indicated a strong and positive association parental absence and adolescent delinquency. The study also revealed that affiliation with delinquent peers could be a predictor of delinquency. Spending time with delinquent peers as well as its direct effect on juvenile delinquency was connected with family structure and parental monitoring. The results support the basic argument that association with delinquent peers plays a big role in the development of juvenile delinquency as suggested by the Social learning Theory.
Using social context, psychosocial attitudes, and individual maturity as variables, Little and Steinberg [13] assessed these factors and individual maturity on the likelihood of illegal drug involvement among urban adolescents. The study revealed five factors that contribute in the increase of opportunity for urban youth to engage in drug selling - low parental monitoring, poor neighborhood conditions, low neighborhood job opportunity, parental substance use or abuse, and high levels of peer group deviance. When adolescents alienate themselves from conventional goals and commitment to school, the likelihood of grabbing a drug-selling opportunity and frequency of drug selling escalates. Using a developmental perspective, the study revealed that disadvantaged youth who have the least confidence of being able to compete in developmental and legitimate platforms such as in schools and work will find drug dealing more attractive socially and economically. The social separation of youth from school and conventional goals such as jobs, career, and parenthood increases their possibility of participating in illicit drug markets.

The study of Johnson et al. [14] cited that illegal drug use escalated in the inner city from 1960s to 1990s while violence related to drug use and selling increased sharply in the 1980s. The complexity of drug-dealing organizations brings economic implications in such a way that drug selling provide substantial income opportunities for inner city youth coming from low-income communities and as a result, legitimate but low-paying jobs are undermined. The study likewise noted that the increase in the arrests of drug sellers did not equate with community safety. Overall, drug abuse in the inner city has resulted to financial problems, poor health and risk of early death, and deterioration of family relationships for most drug users and sellers.

Relative to this, the study of Stanton and Galbraith [15] provided an overview of the epidemiology and consequences of drug trafficking among urban youth and described factors associated with drug trafficking. The respondents of this quantitative study are minority youth from low-income, urban areas in Baltimore, Maryland, USA. Four surveys assessing drug trafficking among early adolescents were used for this review: two communitybased, one school-based, and one multisource, crosssectional survey. Findings of the study revealed that family involvement is one of the external factors associated with drug trafficking. Youth who perceived that family members and peers are involved in drug trafficking seem to be more likely to have engaged in drug trafficking themselves and that this practice is the only way for them to earn money for their perceived social-economic 
obligations. Impaired parent-adolescent communication has also been implicated in drug trafficking by boys. Moreover, endorsement of a need to be "popular" has also been found to correlate with intention to traffic by boys.

Finally, the study of Sharma et al. [16] examined the current trends of substance use in juveniles-under-enquiry in New Delhi, India and establishes the relationship of substance use and criminal behavior. It also explored the predictor variables that would contribute toward an explanatory model of sociodemographic correlates with criminality and identifies contextual factors related to substance use and criminality among the sample studied. Findings of the study showed that the history of crime and substance use in family is another predictive variable that has an influence on antisocial behavior among the juveniles-under-enquiry. Parents with a criminal history are seen to be a contributing factor in the juvenile's initiation to crime, and the patterns of crime are transmitted from one generation to another. Results also highlighted that the presence of abusive father, physical abuse, presence of a stepparent, and substance use in the family are seen to be common family factors which may act as predictive variables in the antisocial behavior among the sample studied.

\section{MATERIALS AND METHODS}

\section{Research Design}

The study utilized the descriptive design using a qualitative approach particularly the narrative research design.

\section{Participants}

The participants of the study were purposively chosen from the population of Children in Conflict with Law (CICL) in the Province of Batangas under the care of the social welfare and development office. The participants were male and female custodies of the Bahay Aruga in Nasugbu, Batangas and Bahay Pag-asa in Lipa City and Tanauan City whose involvement in drugs either as a user or courier was during the age range of below 18 years old as shown in Table 1:

Table.1: Participants' Profile

\begin{tabular}{|l|c|c|l|l|}
\hline & Present Age & $\begin{array}{c}\text { Age of } \\
\text { Involvement } \\
\text { in Drugs }\end{array}$ & Sex & $\begin{array}{l}\text { Nature of } \\
\text { Drug- } \\
\text { Case }\end{array}$ \\
\hline A & 17 years old & 14 years old & Male & $\begin{array}{l}\text { Runner/P } \\
\text { usher }\end{array}$ \\
\hline B & 18 years old & 15 years old & Male & $\begin{array}{l}\text { Courier/ } \\
\text { User }\end{array}$ \\
\hline
\end{tabular}

ISSN: 2456-7620

https://dx.doi.org/10.22161/ijels.56.25

\begin{tabular}{|l|l|l|l|l|}
\hline C & 18 years old & 11 years old & Male & $\begin{array}{l}\text { User/ } \\
\text { Pusher }\end{array}$ \\
\hline D & 17 years old & 15 years old & Male & $\begin{array}{l}\text { User/ } \\
\text { Pusher }\end{array}$ \\
\hline E & 18 years old & 15 years old & Male & Pusher \\
\hline F & 18 years old & 16 years old & Female & Courier \\
\hline G & 16 years old & 15 years old & Female & $\begin{array}{l}\text { User/ } \\
\text { Pusher }\end{array}$ \\
\hline H & 18 years old & 15 years old & Female & $\begin{array}{l}\text { User/ } \\
\text { Courier }\end{array}$ \\
\hline
\end{tabular}

Data Gathering Instruments

The interview questions were developed to investigate why children commit crimes. As such, the development of the questions focused on eliciting episodic narratives of the experiences of participants to identify the recurring themes from their life stories through open-ended and semistructured questions. After expert validation, the questionnaire was pilot tested to identify flaws, limitations, and weaknesses in the interview design. In this case, a pilot test interview was done with former child custody of Bahay Aruga in Nasugbu, Batangas. Aside from the interviews, researchers likewise wrote notes about their observations and interpretations of the story told as well as notes from conversations with the social workers assigned with the concerned CICL. The notes were useful in keeping a record of the participant's profile and prevent misinformation as a result of relying to memory only [17].

\section{Data Collection}

To collect narrative data, personal interview was employed. To do this, a letter of request addressed to the Municipal or City Mayor, as the case may be, was prepared and submitted through the office of social welfare and development. After approval was obtained, the researchers coordinated with the concerned social worker in-charged of CICL cases to identify possible participants of the study based on criteria such as being a current custody of the Bahay Pag-asa at the time of the conduct of the study, has drug-related case (either as courier or user), and age during the commission of crime was below 18 years old.

After the possible participants were identified, a schedule of personal interview was arranged through the social worker in-charge of the custodies. Informed assent were explained to the participants and since the children were custodies of the Bahay Pag-asa, the consent was likewise signed by the social worker as the guardian of the 
children. Privacy and anonymity of the respondents was assured and commitment was made that collected data will only be used in the context of the study.

After the availability of the participants was finalized, the interviews were conducted inside the premises of Bahay-Pagasa. The participants were reminded that the interview will be recorded digitally via an application on the researchers' cell phones and that they could make a request to stop the interview at any time. Afterwards, recorded interviews were transcribed and coded.

Data Analysis

Data gathered through transcribed interviews and researchers' notes were analyzed using coding and narrative analysis particularly following the HolisticContent Approach [18]

After the transcribed data was grouped according to episodes of each of the participant's story, they were coded accordingly to identify the story's main focus per episode. Afterwards, the narrative focal themes were categorized per episode and per participant followed by the identification of the major themes to develop a coherent story of why children commit crimes. The themes were anchored in Thornberry's Interactional Theory particularly the early and mid-adolescence period.

\section{RESULTS AND DISCUSSION}

\section{Narrative Themes from the Lived Experiences of CICL}

Based on the results of the coded transcripts from the interview, the table below describes the themes that emerged from the lived experiences of children in conflict with law grouped according to the gender of the participants.

\subsection{Overall Narrative Theme for Male CICL - The lack of parental attachment and bond has reinforced influence of delinquent peers and adoption of deviant behaviors}

According to the Interactional Theory of Thornberry, delinquency can be better explained by looking into the reciprocal relationship between social control and social learning [19] in such a way that when social bonds are weakened, exposure to delinquent behavior becomes stronger, which in return weakens conventional social bonds. The male CICL in this study are all characterized as having come from broken families mostly with series of step-fathers and step-siblings due to death, violence, or abandonment, and consider their families as poor. This has resulted to pursuit of attention and sense of belongingness outside the home, particularly among peers. Below are the subthemes that support the overall narrative themes for Male CICL

\subsubsection{Desire to belong to a family through his friends}

Participant A has resorted to the company of his friends, spends more time outside the home because he has no direct supervision or control of parents. His so called friends had been his constant companion, though he is with his older half-brother also most of the time, he does not consider him as a source of authority, but as one of his peers. This result concord with the British Psychological Society's view [7], which states that belongingness, is an emotional need to be accepted in a group. Whether it is family, friends, co-workers, a religion, or something else, people tend to have an inherent desire to belong and substance use and addiction somehow provide drug users a new social identity and sense of belonging.

\subsubsection{Drug Usage as a Coping Mechanism}

As the eldest in the family, participant B assumed bigger responsibility when his parents separated due to violence and drugs which he witnessed at a very young age. After the separation of his parents, participant B assumed the role of his mother, having to take care of his younger siblings and manage the house, while his mother had to assume the role of a provider for their family. He lived a dichotomous life - one which has to be responsible and dependable and the other as someone who feels a sense of emptiness and loss. To address this, he sought the company of peers who provided him an opportunity to escape through drug usage. The findings runs parallel with Sinha's study [8], which view drug use and abuse as a coping strategy to deal with stress, to reduce tension, to self-medicate, and to decrease withdrawal-related distress.

\subsubsection{Desire to be accepted and to belong}

Participant $\mathrm{C}$ is the youngest and the only son of his mother and father but he has step siblings on both sides of his parents. He grew up with his mother and step-father (the third husband of his mother). Even as a child (10 years old), there was no parental authority imposed on him; he lost interest in school and as such he spent more of his time with peers. When his mother died, no one took custody of him and so he spent more time with peers and adults who were involved in drugs. Overall, the statements of Participant $\mathrm{C}$ invoke a need to belong, to be recognized and accepted of which he found with peers and drugs. This is in consonance with Fuligni and Eccles' study [9], which underscored the concept of extreme peer orientation extreme peer orientation wherein adolescents put high value to peer acceptance and recognition as well as 
maintenance of peer network to the point of parental disobedience and personal growth obstruction.

\subsubsection{Drug trade as a source of financial security}

Participant D was accustomed to poverty. He grew up in a community characterized by informal settlers and normalcy of crimes. As the only male among his 2 other siblings from different fathers coupled with a family tragedy, participant A assumed the role of provider for his family. As witnessed from his community and peers, there is a possible escape from poverty through drugs. According to Simpson and Akers [20], the theory of social learning has four major concepts namely differential association which is the exposure of an individual to socially acceptable definitions which may be favorable or not to an acceptable or not behavior; definitions which pertains definition or attitude one puts towards a particular behavior; differential reinforcement which refers to how rewards and punishments that follow a behavior are equated; and lastly, imitation which is the copying of similar behavior observed in others. Furthermore, this finding concords with Johnson et al's study [14], which emphasized that drug selling provide substantial economic opportunities for inner city youth coming from lowincome communities and as a result, legitimate but lowpaying jobs are undermined.

\subsubsection{Sense of Worthiness found in Drugs}

Participant E spent most of his early childhood in a family and community where drugs seem normal. As a middle child out of nine children, he grew up under the custody of an extended family member who was already involved in drugs as a user and pusher. Having lived a life of idleness due to absence of parental guidance and control and lack of interest in school, he found a sense of worth and purpose in drug trade. It provided him a source of power, authority and influence over his peers and even adults. This result is in accordance with Little and Steinberg's [13] view, which noted that from a developmental perspective, the potential social and economic pay-offs from drug dealing are most attractive for those disadvantaged adolescents who have the least confidence in their potential to compete in developmentally appropriate arenas of opportunity such as in school and work environments.

Generally, the overall focal themes and narrative themes derived from the live experiences of male CICL points to the relationship of family factors and delinquent peer influence to delinquent behavior. As indicated in many criminological researches, familial factors involve key roles responsibilities that parents should espouse such those related to child guidance and monitoring, child discipline, child involvement, and modeling of good behaviors for children to emulate [19]. The effect of these family factors to delinquency can be viewed as either protective perspective or risk perspective. The former refers to how family may strengthen the bond of an individual to social institutions while the latter pertains to how parents can reinforce delinquency in by children by engaging themselves in deviant or criminal behavior. When the former weakens which means the family's function as a positive social bond diminishes, then association with delinquent peers, wrong modeling, and reinforcement of delinquent tendencies will increase [19].

The emotional ties that bind parents and children are important source of social control. The emotional bond between parents and children allows the convergence of conventional ideals and expectations. The weakening of these bonds increases the likelihood of delinquency. The Interactional Theory of Thornberry emphasizes the element of age in delinquency. Early adolescence or the period from about 11-13 years old is considered the beginning of delinquency. During this time, the family should be able to bind the youth to established institutions to reduce the possibility of delinquency. As an individual reaches the age of 15-16 years old, commonly known as mid-adolescence and the period when the rates of delinquency reaches its highest peak, parental bonds decreases while peer influence increases. Furthermore, Thornberry posits that delinquent behaviors occur due to delinquent peer association and that those who exhibit delinquent behaviors continuously associate with delinquent peers [5]

1.2 Overall Narrative Theme for Female CICL - The absence of maternal guidance and model as well as experience of violence inside the home has catalyzed the desire to escape and strengthen attachment to delinquent peers

Previous researches on delinquency and gender indicate that gender difference in the commitment of crime remains constant, that is men will mostly like commit crimes than women [19]. However, Interactional Theory argues that social structures may shape delinquency differently for men and women. The female CICL in this study all came from a family that lacks positive maternal model or influence and they were exposed or have experienced violence inside the home, which may have prompted them to run away and seek a "family" among peers. Below are the subthemes that support the overall narrative themes for female CICL

\subsubsection{Act of Rebelliousness towards the mother}


At an early age, Participant $F$ had developed ill-feelings towards her mother because of the latter's involvement in drugs, which she perceived as the cause of their family's misery. Because her parents separated when she was young, she grew up with her grandmother and likewise had been lured to enter pre-marital relationships at an early age, which provided her an opportunity to escape her mother's custody. Her personal involvement in drugs has further intensified her resentment towards her mother. This result supports Okundaye, et al's study [10], which disclosed that youth involved in drug-selling expressed stronger sentiments of anger when discussing their mother or father in the interview. They noted that there is an abundance of research that identifies an influence of parents and family on youth's decision to sell drugs

1.2.2 Accustomed to normalcy of drugs and violence in the family

Participant G grew up in a home and community where drug use and selling is a norm. With the leniency accorded by her father's, brothers' and other family members' involvement in drugs coupled with the absence of maternal guidance (due to sickness), she spent most of her time with peers who were also involved in delinquent activities such as drugs, bullying, riots, physical injury, and more. This created a ripples-effect which resulted to her becoming a mother at 15 years old and being involved in drug pushing to support her child. This is in line with Sharma et al's study [16], which highlighted that the history of crime and substance use in family as another predictive variable that has an influence on antisocial behavior among the juveniles-under-enquiry. Family condition leading to crime is seen to be an important factor in this study. Family history of crime and history of substance use in the family were found to have a positive correlation with substance use and criminal behavior among the sample studied.

\subsubsection{Lack of parental guidance and maternal influence}

Participant $\mathrm{H}$ lost his father, whom she was very fond of, at an early age. Initially left to the care of their mother who was always not at home, she was pushed to the company of peers whom she considered as a family. The interview with her concerned social worker likewise revealed that their office have not even met her mother even during the meetings they have set for participant H's case. Without a father and an absentee mother, she was stopped schooling at 8 years old (Grade II) and had early pregnancy at age 15. During the few times she spent with her mother, she experienced physical abuse and violence. The rest of her family is also implicated in various drugrelated cases. This finding bears semblance with Alboukordi et al's study [12], which noted that spending time with delinquent peers as well as its direct effect on juvenile delinquency was associated with family structure and parental monitoring.

The overall focal themes and narrative themes derived from the live experiences of female CICL reveal the key role of a maternal model and guidance when it comes to delinquency among female children. This is amplified by the exposure and experience of violence and abuse of the female delinquents.

According to the interactional theory, male and female delinquents vary in their routes to delinquency path. Trajectories of female delinquency point to family attachment while male delinquency is towards delinquent peers [19]. A review of the said theory argued that gender differences in delinquency can be viewed using the lens of Trait, Family structure, and Social process perspectives [19] [21]. The trait perspective looks at the physical and mental traits of male and female; family structure contends that the gender difference in the commission of crime is due to social norms and ideologies practiced in the family; and social process disputes that the difference lies in the different exposure to delinquent environments and social reactions. Family structure perspective posits that women are closely monitored at home which is why they are less likely to be delinquent than men.

More so, Social process perspective indicates that because males are more exposed situations and opportunities for delinquency, then they are more likely to commit crime than females. It should be noted that all of the female CICL participants in this study lack parental guidance particularly maternal model to emulate; thus loosening their bond to conventional values and restraint. In a separate interview with their social worker, two of the female CICL in this study are members of an all-girls gang. As stated by Steffensmeier [21], girls seek gang membership as early as the 1920's and through this association, they try to find solutions for their problems of gender and class, to name a few. Another angle in the social process perspective leads to delinquent labeling or self-fulfilling prophesies. Traditionally, norms of conduct for girls are stricter; hence, offenses, may it minor or more serious, lead to harsh penalties and stigmatization. With this, the likelihood of delinquency increases. In all three female CICL in this study, two are exposed and experienced themselves violence and physical abuse in the family. These two are also members of an all-girls gang in their locality.

Again, the study was anchored on Terence P. Thornberry's Interactional Theory which is based on the premise that human behavior occurs in social interaction 
and can be explained by models that focus on interactive processes [5]. Thornberry's Interactional Theory provides theoretical guidance and a point of departure for the study. The said theory underscored that delinquent behavior is formed by the relationships with other people and social institutions over time. That is, delinquent behavior is explained as a causal network not only affected by social factors but also affecting the development of those social factors.

Information with reference to the participants' motives to start and continue using and selling drugs emerged as well as insights on possibly viewing drug selling as an addictive behavior after partaking in the activity for a long period of time. Pertinent information was identified in this study namely: the age they started using and selling drugs, personal narratives, recollections, and perspectives from being users and dealers themselves.

Based on the personal narratives of the respondents, the motivations for starting to use drugs and be involved in drug trade include: being pushed towards the company of friends due to lack of parental authority and guidance; parental conflict forced him to assume bigger responsibilities and caused feeling of emptiness; sense of acceptance and feeling of belongingness is found in the community and peers involved in illegal drugs; escape from poverty was found in illegal drug trade; sense of entitlement accorded by involvement in drug trade; delinquency and involvement in drugs as act of rebellion against the mother; found normalcy in drugs and violence from family and community; and lack of maternal figure to emulate and provide guidance.

Likewise, the motivations to continue using drugs and be involved in drug trade consist of: choosing friends over family; drugs became a coping mechanism to escape loneliness; drug usage as a solution to unmet needs and problems; drug trade involvement provided a way for a more comfortable life for his family; sense of worth (for self, family and extended family, friends, and community) is found on the trade of drugs; intensified anger towards mother as the cause of her present situation; intensified negative attitude and behavior as a result of peer influence; and friends became family for her.

The general focal themes that emerged out the episodic focal themes include: the desire to belong to a family through his friends; drug usage as coping mechanism; desire to be accepted and to belong; drug trade as source of financial security; and sense of worthiness is found in drug trade.

From the aforecited focal themes emerged the overall narrative themes out of the males' and females' personal narratives, which consist of: the lack of parental attachment and bond that reinforced the influence of delinquent peers and adoption or delinquent behavior among the male CICL; and the lack of maternal guidance and model as well as exposure to violence inside the home that catalyzed desire to escape and strengthen attachment to peers of the female CICL.

Finally, these generalizations provide support for Thornberry's Interactional Theory which asserts that human behavior occurs in social interaction and can be explained by models that focus on interactive processes. It emphasized that delinquent behavior associated with drug use and drug dealings are formed by the relationships with other people specifically their peers and social institutions like their families and communities over time. That is, drug use and drug dealing are explained as a causal network affected by social factors. In this study, the indicators for both social control and social learning were included. Family attachment represented social control while deviant peer association represented social learning. The study examined the reciprocal relations among family attachments, deviant peer association, as well as delinquency across the lives of the eight participants.

2. Gender-based Framework as basis of an intervention program to address the issue of criminality among children

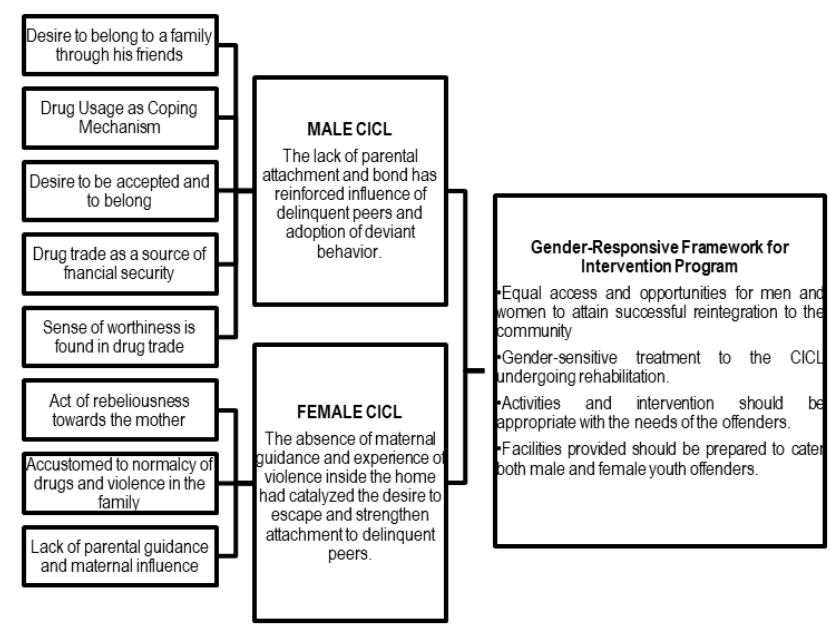

Fig. 1: Gender-based Framework as basis for intervention Program for CICL

Gender responsive intervention program for Child in Conflict Law (CICL) remains a gray area in the justice system in different countries including the Philippines as revealed in the Evaluation of the Intervention and 
Rehabilitation Program in Residential Facilities and Diversion Programs for Children in Conflict with the Law last 2015 [6]. Most programs were tailored depending on the needs of male offenders since they comprised majority of the CICL population as reported by the Department of Social Welfare and Development. Admittedly, facilities and responsive programs on the needs of female offenders are likewise lacking [6]. Being discounted for the past years, female offenders were no longer obscure in the justice system, thus, a need for crafting a gender responsive intervention program and activities is needed [22]

From the formulated focal and narrative themes, it was noted that male and female CICL differs in how they were involved in drug related crimes. Male CICL's involvement was due to lack of parental attachment and bond which reinforced the influence of their delinquent peers and further adopt deviant behaviors such as drug use. In the contrary, Female CICL's involvement was due to the absence of maternal guidance and exposure to violence inside their home that pushed them to escape and strengthen their attachment to the delinquent peers that they see as family

With these results, a gender appropriate intervention program must be designed to answer the specific needs of the CICL wherein they could have equal access to opportunities and programs to attain successful reintegration to the community with avoidance of recidivism. DSWD as the principal office mandated to develop Gender-sensitive treatment for CICL undergoing rehabilitation may consider devising activities and programs addressing different capacities and needs of both male and female. Equal participation on the activities provided during the intervention by both male and female CICL should also be prioritized. Staffs and house parents dealing with the CICL should be oriented of gender sensitive treatment to the male and female custodies of Department of Social Welfare and Development (DSWD).

In addition, the causes of delinquent behavior should be addressed so both male and female CICL would be successful in completing the program with activities appropriate for specific needs of the offenders. Like for instance, one of the participants in the study is already a mother at a very young age, a program addressing her role as a mother through educating about parental rearing after the intervention must be addressed. Also, female participants are mostly victim and exposed to domestic violence which should be addressed in relation to prior abuse through psychological evaluation and therapy addressing a possible trauma. In addition, facilities for female CICL should also be prioritized by the government ISSN: 2456-7620 since few facilities, mostly by Non-Government Organization (NGO), are available to cater the female CICL.

Overall, a gender-responsive approach is to be prioritized in catering CICL cases. This should be achieved by active participation of different agencies providing intervention to the CICL such as the DSWD through its local offices and the Local government units extending to the barangay levels which plays a role in the community based diversion programs and rehabilitation programs of the DSWD.

\section{CONCLUSION}

The causes of male and female offending among Children in Conflict with Law revealed the need for a Gender Responsive Framework in the development of gendersensitive programs that allow equal access and opportunities for men and women to attain successful reintegration to the community; psychological treatment to the CICL undergoing rehabilitation, appropriate activities and intervention according to the needs of the offenders; and provision of facilities to cater both male and female youth offenders. These results may be useful to the provincial social welfare and development office to consider lobbying for the construction of Bahay-Pagasa with facilities for female custodies in various municipalities of the province. They may also push for the institutionalization of licensed psychologists or to fund relevant training and tools for social workers to improve their counseling and intervention skills in handling CICL cases. Furthermore, they may institutionalize programs that can help the parents of CICL cases improve their parenting skills and build better relationships with their children

The barangay officials through the assistance of the social welfare and development office in various municipalities in Batangas may develop intervention programs for CICL that allows equal access for both male and female youth offenders especially activities that help address early parenting and pregnancy. Finally, the study may further be improved by considering other lens and methodologies to understand more deeply why children commit crimes.

\section{ACKNOWLEDGEMENTS}

The authors wish to acknowledge the support accorded to them by the Batangas State University in terms of funding the conduct of this research. Further, they would like recognize the support of the Provincial and Municipal 
Social Welfare and Development Offices in the concerned municipalities in Batangas for allowing them to conduct this study and interview children in conflict law under their custody. Finally, the authors extend their sincerest thanks to those Children in Conflict with Law for sharing with them their stories.

\section{REFERENCES}

[1] Loeber, R., and Farrington, D. (2000). Young children who commit crime: Epidemiology, developmental origins, risk factors, early interventions, and policy implications. Development and Psychopathology, 12(4),

737-762.

https://doi.org/10.1017/S0954579400004107

[2] Juvenile Delinquency: World Youth Report (2003). Retrieved from http://www.un.org/esa/socdev/unyin/documents/ch07. pdf .

[3] Bilog, Freddy E. (2014). Implementation of the Juvenile Justice and Welfare Act of 2006 (RA 9344): Inputs to Policy Amendments. Asia Pacific Journal of Multidisciplinary Research, 2(3). 54-69. Retrieved from http://research.lpubatangas.edu.ph/wpcontent/uploads/2014/10/APJMR-Implementation-ofthe-Juvenile-Justice.pdf

[4] Breaking Rules: Children in Conflict with the Law and the Juvenile Justice Process The Experience In The Philippines. (2004). Save the Children UK: Quezon City, Philippines. Retrieved from https://resourcecentre.savethechildren.net/sites/default /files/documents/3235.pdf

[5] Thornberry, T.P. (1987). Towards an interactional Theory of Delinquency. Criminology. 25(4), pp 863892. https://doi.org/10.1111/j.1745-

[6] Yang, S. X., Veloso, D., Diaz, B., Aldaba, F. and Aristion, H. (2015). Evaluation of the Intervention and Rehabilitation Program in Residential Facilities and Diversion Programs for Children in Conflict with the Law. Retrieved from https://www.unicef.org/evaldatabase/files/Philippines 2015-004_Final_Report.pdf

[7] The British Psychological Society (2019). Addiction and the Importance of Belonging; Retrieved from: https://thepsychologist.bps.org.uk/volume-31/may2018/addiction-and-importance-belonging

[8] Sinha, R. (2008). Chronic Stress, Drug Use, and Vulnerability to Addiction. Annals of New York Academy of Sciences, Addiction Reviews. 1141(1), pp. 105-130. DOI: 10.1196/annals.1441.030

[9] Fuligni, A. J., \& Eccles, J. S. (1993). Perceived parent-child relationships and early adolescents'

ISSN : 2456-7620

https://dx.doi.org/10.22161/ijels.56.25 orientation toward peers. Developmental Psychology, 29(4), 622-632. https://doi.org/10.1037/0012$\underline{1649.29 .4 .622}$

[10] Okundaye, J., Cornelius L.J., and Manning, M. (2001). Drug Trafficking among African American Youth: Risk Factors for Future Incarceration. Article in Journal of African American Studies 5(4):39-63. DOI: $10.1007 / \mathrm{s} 12111-001-1019-\mathrm{x}$

[11] Glenn, L. and Maria C. (2019). Cause \& Effect Essay: Rebellious Behavior in Teenagers. Retrieved from: https://www.scholaradvisor.com/essayexamples/cause-and-effect-essay-rebellious-behaviorin-teenagers/

[12] Alboukordi, S., Robabeth, N., and Javad, K.S. (2012). Predictive Factors for Juvenile Delinquency: Role of Family Structure, Parental Monitoring and Delinquent Peers. International Journal of Criminology and Sociological Theory, Vol. 5, No. 1, June 2012, 770$777 . \quad$ Retrieved from https://ijcst.journals.yorku.ca/index.php/ijcst/article/vi ew/35180

[13]Little, M. and Steinberg, L. (2006). Psychosocial Correlates of Adolescent Drug Dealing in the Inner City: Potential Roles of Opportunity, Conventional Commitments, and Maturity. J Res Crime Delingq. Retrieved from https://www.ncbi.nlm.nih.gov/pmc/articles/PMC2792 $\underline{760 /}$

[14] Johnson, B. D., Terr, W., Kojo A. D., and Sanabria, H. (1990). Drug Abuse in the Inner City: Impact on Hard-Drug Users and the Community (From Drugs and Crime, V 13, P 9-67, 1990, Michael Tonry and James Q Wilson, eds. -- See NCJ-125241). Retrieved from

http://www.ncjrs.gov/App/publications/abstract.aspx?I $\mathrm{D}=125242$

[15] Stanton, B. and Galbraith, J. (1994). Drug Trafficking Among African-American Early Adolescents: Prevalence, Consequences, and Associated Behaviors and Beliefs. Pediatrics Vol. 93, No. 6, June 1994. Retrieved from https://pediatrics.aappublications.org/content/pediatric s/93/6/1039.full.pdf

[16] Sharma, S., Gautam, S. and Barkataki, B. (2016). Substance use and criminality among juveniles-underenquiry in New Delhi. Indian J Psychiatry. 2016 AprJun; 58(2): 178-182; Retrieved from: https://www.ncbi.nlm.nih.gov/pmc/articles/PMC4919 $\underline{9621}$

[17] Saldaña, J. (2009). The Coding Manual for Qualitative Researchers (3rd ed.) Sage Publications, 
Nov-Dec 2020 / Available online: https://ijels.com/

Inc. $\quad$ Retrieved from

https://www.academia.edu/11310253/The_coding_ma

nual for qualitative researchers

[18]Lieblich, Amia , Rivka Tuval-Mashiach and Tamar Zilber (ed). (1998). The Holistic-Content Perspective.

https://dx.doi.org/10.4135/9781412985253.n4

[19]Lee, S. (2003). Testing Thornberry's interactional theory: the reciprocal relations. Iowa State University-Retrospective Theses and Dissertations. Retrieved from https://lib.dr.iastate.edu/rtd/601

[20] Simpson, J. and Akers, R. (2000). Social Learning and Social Structure: A General Theory of Crime and Deviance. Social Forces. 78. 1171. DOI $10.2307 / 3005950$

[21] Steffensmeier, D. and Allan, E. (1996). Gender and Crime: Toward a Gendered Theory of Female Offending. $\quad$ Retrieved from https://www.researchgate.net/publication/234838484 Gender_and_Crime Toward_a_Gendered Theory_of Female_Offending

[22] Covington, S.S. and Bloom, B.E. (2006). GenderResponsive Treatment and Services in Correctional Settings. Women and Therapy, Elaine Leeder, Editor, (2006) Vol. 29, No. 3/4, pp. 9-33. Retrieved from https://www.stephaniecovington.com/assets/files/FIN ALC.pdf 